Discharge Location and Outcomes after Transcatheter Aortic Valve Implantation

Romy Sweda MD , Stephan Dobner MD, PhD, Dik Heg PhD , Jonas Lanz MD, MSc, Daniel Malebranche MD, Bettina Langhammer MD , Taishi Okuno MD , Fabien Praz MD , Lorenz Räber MD, PhD , Marco Valgimigli MD, PhD , David Reineke MD , Thomas Pilgrim MD, MSc , Stephan Windecker MD , Stefan Stortecky MD

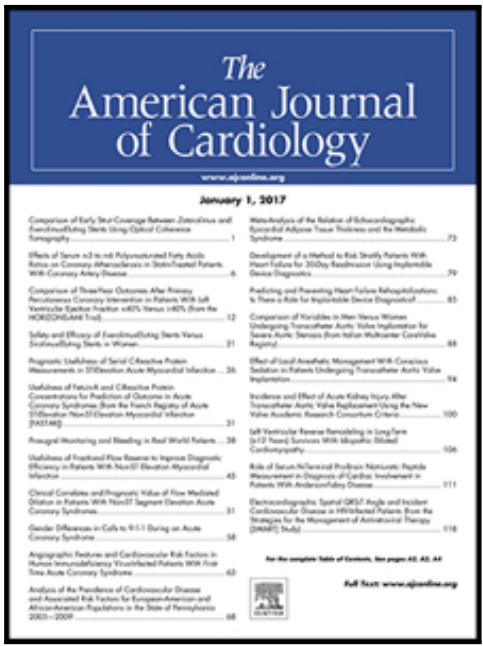

PII:

DOI: S0002-9149(20)31191-7

Reference: https://doi.org/10.1016/j.amjcard.2020.10.058 AJC 24950

To appear in: The American Journal of Cardiology

Received date:

24 August 2020

Revised date: 16 October 2020

Accepted date: 16 October 2020

Please cite this article as: Romy Sweda MD, Stephan Dobner MD, PhD, Dik Heg PhD, Jonas Lanz MD, MSc , Daniel Malebranche MD , Bettina Langhammer MD , Taishi Okuno MD , Fabien Praz MD , Lorenz Räber MD, PhD , Marco Valgimigli MD, PhD, David Reineke MD , Thomas Pilgrim MD, MSc, Stephan Windecker MD, Stefan Stortecky MD, Discharge Location and Outcomes after Transcatheter Aortic Valve Implantation, The American Journal of Cardiology (2020), doi: https://doi.org/10.1016/j.amjcard.2020.10.058

This is a PDF file of an article that has undergone enhancements after acceptance, such as the addition of a cover page and metadata, and formatting for readability, but it is not yet the definitive version of record. This version will undergo additional copyediting, typesetting and review before it is published in its final form, but we are providing this version to give early visibility of the article. Please note that, during the production process, errors may be discovered which could affect the content, and all legal disclaimers that apply to the journal pertain.

(C) 2020 Published by Elsevier Inc. 


\section{Discharge Location and Outcomes after Transcatheter Aortic Valve Implantation}

Romy Sweda, $\mathrm{MD}^{\mathrm{a}^{*}}$; Stephan Dobner, MD, $\mathrm{PhD}^{\mathrm{a}^{*}}$; Dik Heg, $\mathrm{PhD}^{\mathrm{b}}$; Jonas Lanz, MD, MSc ${ }^{\mathrm{a}}$;

Daniel Malebranche, $\mathrm{MD}^{\mathrm{a}}$; Bettina Langhammer, $\mathrm{MD}^{\mathrm{c}}$; Taishi Okuno, $\mathrm{MD}^{\mathrm{a}}$; Fabien Praz, MD ${ }^{\mathrm{a}}$; Lorenz Räber, $\mathrm{MD}, \mathrm{PhD}^{\mathrm{a}}$; Marco Valgimigli, $\mathrm{MD}, \mathrm{PhD}^{\mathrm{a}}$; David Reineke, $\mathrm{MD}^{\mathrm{c}}$;

Thomas Pilgrim, MD, MSc ${ }^{\mathrm{a}}$; Stephan Windecker, MD ${ }^{\mathrm{a}}$; and Stefan Stortecky, MD ${ }^{\mathrm{a}}$

*Drs. Sweda and Dobner contributed equally to this manuscript

a Department of Cardiology, Inselspital, Bern University Hospital, University of Bern, Bern, Switzerland

${ }^{\mathrm{b}}$ CTU Bern, University of Bern, Bern, Switzerland

${ }^{c}$ Department of Cardiovascular Surgery, Inselspital, Bern University Hospital, University of Bern, Bern, Switzerland

Running title: Discharge location and outcomes after transcatheter aortic valve implantation

Address for correspondence: Stefan Stortecky, MD

Associate Professor of Cardiology

Department of Cardiology

Inselspital - Bern University Hospital

University of Bern

3010 Bern, Switzerland

Tel: (+41 31) 6328352

Fax: (+41 31) 6641069

Email: stefan.stortecky@insel.ch 


\section{Abstract}

The relationship between discharge location and outcomes after transcatheter aortic valve implantation (TAVI) is largely unknown. Thus, the objective of this study was to investigate the impact of discharge location on clinical outcomes after TAVI. Between August 2007 and December 2018, consecutive patients undergoing transfemoral TAVI at Bern University Hospital were grouped according to discharge location. Clinical adverse events were adjudicated according to VARC-2 endpoint definitions. Of 1,902 eligible patients, 520 $(27.3 \%)$ were discharged home, $945(49.7 \%)$ were discharged to a rehabilitation clinic and $437(23.0 \%)$ were transferred to another institution. Compared with patients discharged to a rehabilitation facility or another institution, patients discharged home were younger $(80.8 \pm 6.5$ vs. $82.9 \pm 5.4$ and $82.8 \pm 6.4$ years), less likely female (37.3\% vs. $59.7 \%$ and $54.2 \%)$ and at

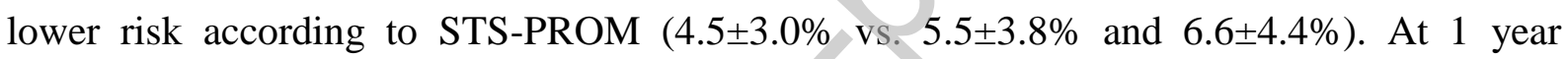
follow-up, patients discharged home had similar rates of all-cause mortality $\left(\mathrm{HR}_{\mathrm{adj}} 0.82\right.$; 95\% CI 0.54-1.24), cerebrovascular events $\left(\mathrm{HR}_{\mathrm{adj}} 1.04 ; 95 \% \mathrm{CI} 0.52-2.08\right)$ and bleeding complications $\left(\mathrm{HR}_{\mathrm{adj}} 0.93 ; 95 \% \mathrm{CI}\right.$ 0.61-1.41) compared to patients discharged to a rehabilitation facility. Patients discharged home or to rehabilitation were at lower risk for death $\left(\mathrm{HR}_{\text {adj }} 0.37 ; 95 \% \mathrm{CI} 0.24-0.56\right.$ and $\left.\mathrm{HR}_{\text {adj }} 0.44 ; 95 \% \mathrm{CI} 0.32-0.60\right)$ and bleeding $\left(\mathrm{HR}_{\text {adj }}\right.$ 0.48; 95\% CI $0.30-0.76$ and $\mathrm{HR}_{\text {adj }} 0.66$; 95\%CI 0.45-0.96) during the first year after hospital discharge compared to patients transferred to another institution. In conclusion, discharge location is associated with outcomes after TAVI with patients discharged home or to a rehabilitation facility having better clinical outcomes than patients transferred to another institution.

Key words: aortic stenosis, transcatheter aortic valve implantation, discharge location, clinical outcomes

Clinical Trial Registration: https://www.clinicaltrials.gov. NCT01368250. 


\section{INTRODUCTION}

A structured approach to peri-operative care facilitates early recovery in patients undergoing open-heart surgery and may reduce post-operative adverse events and hospital length of stay. ${ }^{1}$ After hospital discharge, dedicated in-patient cardiac rehabilitation programs offer uninterrupted care following cardiac surgery to ensure appropriate wound care, improve mobilization and restore physical strength. Moreover, cardiac rehabilitation is associated with a relevant reduction in all-cause mortality after coronary artery bypass graft surgery, ${ }^{2}$ and a substantial improvement in physical capacity after heart valve surgery. ${ }^{3}$ During the last decade, transcatheter aortic valve implantation (TAVI) has emerged as therapeutic alternative to surgical aortic valve replacement among symptomatic patients with severe aortic stenosis across the surgical spectrum of risk. ${ }^{4}$ The substantially lower degree of invasiveness associated with TAVI has led to the evolution of clinical care pathways that ultimately serve to streamline hospital stay, reduce health service utilization and improve clinical outcomes. ${ }^{5,6}$ Adherence to such protocols is associated with effective early ambulation thus facilitating next-day home-discharge in up to $80 \%$ of patients undergoing TAVI. ${ }^{7}$ The relationship between discharge location and outcomes among patients undergoing transfemoral TAVI has been insufficiently investigated yet, and is the aim of the present study.

\section{METHODS}

Between August 2007 and December 2018, consecutive patients undergoing transfemoral TAVI at Bern University Hospital were entered into the Bern TAVI Registry, which is part of the SwissTAVI Registry (ClinicalTrials.gov identifier NCT01368250). ${ }^{8}$ Patient selection, the procedure and post-procedural care were performed according to local standards and expertise, and followed the recommendation of the multi-disciplinary Heart Team. After TAVI, patients were routinely monitored in an intermediate care unit for a duration of 24-48 hours before being transferred to a cardiology ward. From the ward service, patients were 
either discharged to their home, to a rehabilitation facility, or transferred to the referring regional hospital or another institution. There were no pre-defined disposition criteria and decisions were made on a case to case basis according to medical requirements and personal preferences. The option to participate in a rehabilitation program was offered to all patients and routinely discussed before the intervention as part of the pre-procedural disposition planning. The Bern University Clinical Trials Unit was responsible for central data monitoring and statistical analysis. The study protocol, which was approved by the national ethics committee, was conducted in accordance with the Declaration of Helsinki, and all patients provided written informed consent.

Clinical follow-up and echocardiographic assessment were scheduled at 30 days and 1 year after TAVI. Serious adverse events occurring during the follow-up period were reviewed by an independent clinical event committee and adjudicated according to the recommendations of the Valve Academic Research Consortium (VARC-2). ${ }^{9}$ The primary endpoint of the study was all-cause mortality at one year.

Baseline and procedural characteristics are presented as means ( \pm standard deviation) and counts (\%). Continuous variables were compared with t-tests, and Fisher's tests. Categorical variables were compared using chi-square tests, pairwise across the discharge groups. Clinical outcomes from discharge to one year of follow-up (censoring at death, loss to follow-up or withdrawal of consent) are presented as counts of the first event of each outcome according to discharge location (\% from life-table estimates). These outcomes were compared pairwise across the discharge groups using Cox's regressions. Hazard ratios are presented with $95 \%$ confidence intervals (CI). This was repeated using adjusted Cox regressions, where pairwise hazard ratios were adjusted for age, sex, Society of Thoracic Surgeons Predicted Risk of Mortality (STS PROM), history of atrial fibrillation, left ventricular ejection fraction (LVEF), year of TAVI $(\leq 2010,2011-2013,>2014)$; regurgitation of aortic, mitral and 
tricuspid valves; and peri-procedural events: cerebrovascular events, vascular complications, life-threatening or major bleeding, acute kidney injury (AKI) stage 2 or 3; number of days in the hospital before discharge ( $\leq 3$ vs $4-6$ vs $7-10$ vs $>10$ days). We assumed no risk for missing variables; no adjusted analyses with less than ten events. The outcome analysis was then repeated for pairwise matched-cohorts of discharge groups, using the following variables for propensity score matching: age, sex, STS PROM, atrial fibrillation, LVEF, year of TAVI ( $\leq 2010,2011-2013,>2014)$; regurgitation of aortic, mitral and tricuspid valves; and index hospitalization events: cerebrovascular events, vascular complications, life-threatening or major bleeding, AKI stage 2 or 3 ; number of days in the hospital before discharge ( $\leq 3$ vs $4-6$ vs $7-10$ vs $>10$ days).

\section{RESULTS}

Between August 2007 and December 2018, 1,971 patients underwent transfemoral TAVI. Among the 1,902 study subjects, $49.7 \%$ of patients were discharged to a rehabilitation facility, $27.3 \%$ were discharged home and $23.0 \%$ were transferred to another institution (Figure 1). Changes in hospital discharge disposition during the study period and according to the year of treatment are displayed in Figure 2. Over time, rates of hospital discharge to a rehabilitation facility increased $(2007-201044.1 \%$; $\geq 201751.6 \%)$, whereas rates of discharge to another institution declined $(2007-201035.4 \%$; $\geq 201713.0 \%)(\mathrm{p}<0.001)$.

Baseline clinical characteristics of the study population are provided in Table 1. Patients discharged home were younger $(80.8 \pm 6.5$ vs $82.9 \pm 5.4$ vs. $82.8 \pm 6.4$ years), less frequently female $(37.3 \%$ vs. $59.7 \%$ vs. $54.2 \%)$, and had a lower estimated mortality risk according to the STS PROM (4.5 \pm 3.0 vs. $5.5 \pm 3.8$ vs. $6.6 \pm 4.4)$ compared with patients discharged to a rehabilitation facility or other institution. Baseline clinical characteristics were comparable except for rates of previous cardiac surgery (16.7\% vs. $11.2 \%$ vs. $10.1 \%)$, preprocedure aortic valve area $\left(0.76 \pm 0.23 \mathrm{~cm}^{2}\right.$ vs. $0.71 \pm 0.22 \mathrm{~cm}^{2}$ vs. $\left.0.72 \pm 0.26 \mathrm{~cm}^{2}\right)$ and baseline 
NYHA functional class III and IV (60.8\% vs. $71.3 \%$ vs. $77.1 \%)$ for the respective discharge locations of home, rehabilitation facility and another institution.

Table 2 summarizes procedural characteristics across patient groups. Significant group differences were observed with respect to packed red blood cell transfusion $(7.5 \%$ vs. $11.5 \%$ vs. $17.8 \%)$, and in-hospital length of stay ( $7.2 \pm 3.1$ vs. $8.9 \pm 3.8$ vs. $8.5 \pm 5.5$ days). There were no significant differences with respect to procedure time, total contrast administered and general anesthesia requirements among patients discharged home and those transferred to a rehabilitation facility. Conversely, patients transferred to another institution had a longer procedure duration, more contrast dye administered, and had higher rates of general anesthesia requirements during the procedure compared to patients with discharge home and to a rehabilitation facility, respectively. (Table 2) Peri-procedural adverse events for all three patient groups are provided in Supplemental Table 1.

Clinical outcomes at one year after discharge are presented in Table 3. The primary endpoint occurred in $7.2 \%, 8.9 \%$ and $22.4 \%$ across the three discharge categories of home, rehabilitation and other institution, respectively. (Figure 3). Compared with patients discharged home, those sent to a rehabilitation facility showed no significant differences with respect to death $\left(\mathrm{HR}_{\mathrm{adj}}\right.$ 0.82, 95\%CI 0.54-1.24), cerebrovascular accidents $\left(\mathrm{HR}_{\mathrm{adj}}\right.$ 0.79, 95\%CI $0.47-1.34)$ or bleeding $\left(\mathrm{HR}_{\text {adj. }}\right.$ 0.93, 95\%CI $\left.0.61-1.41\right)$ at one-year follow-up. This observation was confirmed in 974 propensity score matched patients with discharge to home or to a rehabilitation facility ( $\mathrm{n}=487$ per group, Supplemental Tables $\mathbf{2 , 3}$ and 4). There were no significant differences in the risk of death $\left(\mathrm{HR}_{\mathrm{adj}}\right.$. 1.01, 95\%CI 0.62-1.63), cardiac death $\left(\mathrm{HR}_{\text {adj. }}\right.$ 0.87, 95\%CI 0.48-1.60), cerebrovascular events ( $\left.\mathrm{HR}_{\text {adj. }} 0.97,95 \% \mathrm{CI} 0.45-2.06\right)$, or any other endpoints at one-year follow-up. (Supplemental Table 5). Conversely, patients with discharge home and to a rehabilitation facility were at lower risk for death $\left(\operatorname{HR}_{\mathrm{adj}} 0.37\right.$; 95\%CI 0.24-0.56 and $\left.\mathrm{HR}_{\text {adj }} 0.44 ; 95 \% \mathrm{CI} 0.32-0.60\right)$, cardiac death $\left(\mathrm{HR}_{\text {adj }} 0.42\right.$; 95\%CI 0.25- 
0.71 and $\left.\mathrm{HR}_{\text {adj }} 0.45 ; 95 \% \mathrm{CI} 0.30-0.66\right)$ and bleeding $\left(\mathrm{HR}_{\text {adj }} 0.48 ; 95 \% \mathrm{CI} 0.30-0.76\right.$ and $\mathrm{HR}_{\text {adj }}$ 0.66; 95\%CI 0.45-0.96) during the first year after hospital discharge compared to patients with transfer to another institution.

\section{DISCUSSION}

The present study investigates the impact of discharge location on clinical outcomes in patients undergoing transfemoral TAVI. The main findings are as follows:

- One out of four patients with severe aortic stenosis was discharged home after TAVI.

- Increasing rates of hospital discharge to a rehabilitation facility were observed, whereas rates of discharge to another institution declined over time.

- Discharge to home was associated with favorable clinical outcomes and no significant differences in all-cause mortality, stroke or bleeding as compared to patients discharged to a rehabilitation facility.

- During one year after hospital discharge, patients with discharge to another institution had the highest incidence of death, cardiac death and bleeding complications.

Optimization of transitional care is strongly associated with both an improvement in outcomes after major medical or surgical interventions as well as a substantial reduction in healthcare resource utilization. ${ }^{10}$ While patients with valvular heart disease undergoing surgical valve replacement clearly benefit from specific cardiac rehabilitation programs, ${ }^{11,12}$ the impact of cardiac rehabilitation on clinical outcomes in patients undergoing TAVI is less well established.

After transfemoral TAVI, 1 out of 4 patients was discharged into self-care at home, whereas nearly twice that number were discharged into a rehabilitation facility, with a trend of increasing frequency over time (Figure 2). This unexpected finding contrasts with data from other geographical areas, where TAVI was independently associated with a lower probability 
for cardiac rehabilitation referral and participation. ${ }^{13}$ While this observation may partly be explained by the clinical characteristics of this patient population, it is also likely that the lack of robust evidence is driving the variability in cardiac rehabilitation referral. ${ }^{14}$ Indeed, the literature supporting the benefits of cardiac rehabilitation after TAVI is scarce and limited to small observational studies. Recent meta-analyses demonstrated only minor effects on exercise capacity among TAVI patients undergoing rehabilitation ${ }^{11,12}$ and the functional changes did not translate into improvements in clinical endpoints. The findings of our study are consistent with this observation, showing comparable clinical outcomes between patients discharged to a rehabilitation clinic and those discharged into self-care at home.

Most recently, an analysis from the WIN-TAVI Registry provided insights regarding discharge disposition following TAVI in women. In this analysis where the majority of women were directly discharged home, and only one quarter were transferred to another institution, a pathway of home discharge was advocated. ${ }^{15}$ By contrast, an analysis from the U.S. National Inpatient Sample database with 40,900 patients undergoing TAVI between 2012 and 2014, showed that only a minority of women were discharged into self-care at home ${ }^{16}$ which is more consistent with the findings of the present study. While the authors were unable to identify specific reasons for this observation with regards to clinical or procedural characteristics of female patients, they suspect that social and marital status might have confounded the data. Due to their longer life expectancy, elderly females tend to be widowed and live alone with increasing age, ${ }^{17}$ which might have altered the destination of discharge. WIN-TAVI study individuals transferred to another institution had an increased risk of cardiovascular death and stroke at one-year follow-up. ${ }^{15}$ Rates of adverse clinical outcomes were even higher in our patient population, where patients transferred to another institution had the highest risk of death, cardiac death and bleeding complications during the first year after hospital discharge. Pre-existing comorbidities as well as a higher estimated predicted risk of mortality are likely to be responsible for both prolonged medical care and 
worse clinical outcomes during longer-term follow-up. Whether or not early identification of these factors and a concept of pre-interventional rehabilitation ("prehabilitation") results in a reduction of peri-procedural complications and hospital length of stay warrants further exploration.

The results of the present study need to be interpreted in light of the following limitations: Firstly, the results of this study mirror the experience of a single, tertiary care center and the results might not be generalizable to other centers with differences in institutional protocols and discharge practices. Secondly, the data presented in this analysis need to be considered as observational only, and a selection bias in discharge disposition cannot be excluded. However, sophisticated statistical methods were used to adjust for potential confounders and we were able to reproduce results in propensity-score matched cohorts. Thirdly, the study database did not collect social variables including marital status and family or social support, which may play a role in determining discharge mode and timing. As a fourth consideration, patients transferred to another institution were not further evaluated to clarify reasons for this discharge disposition. Indeed, there may have been important clinical considerations that ultimately impact subsequent clinical outcomes. As a fifth consideration, participation in rehabilitation was not prospectively defined and was the result of informed and patient-centered decision making. Finally, as the aim of this study was to evaluate the impact of discharge location on clinical outcomes and rather than investigate the effect of rehabilitation after TAVI, specific data regarding duration and mode of rehabilitation (i.e. in-patient versus ambulatory) were not collected. Future, prospective studies are likely to address the impact of home- and community-based rehabilitation strategies on morbidity and mortality after TAVI. 
In conclusion, TAVI patients who were discharged home had long-term outcomes that were comparable to those discharged to a rehabilitation facility. Home discharge after TAVI may represent a safe and feasible strategy in well-selected patients.

\section{AUTHOR CONTRIBUTIONS:}

Romy Sweda: Conceptualization, Methodology, Validation, Writing - Original Draft

Stephan Dobner: Conceptualization, Methodology, Validation, Writing - Original Draft

Dik Heg: Validation, Formal analysis, Methodology, Writing - Review \& Editing

Jonas Lanz: Investigation, Writing - Review \& Editing

Daniel Malebranche: Investigation, Writing - Review \& Editing

Bettina Langhammer: Investigation, Writing - Review \& Editing

Taishi Okuno: Investigation, Writing - Review \& Editing

Fabien Praz: Investigation, Writing - Review \& Editing

Lorenz Räber: Investigation, Writing - Review \& Editing

Marco Valgimigli: Investigation, Writing - Review \& Editing

David Reineke: Investigation, Writing - Review \& Editing

Thomas Pilgrim: Investigation, Writing - Review \& Editing

Stephan Windecker: Investigation, Resources, Writing - Review \& Editing, Supervision, Funding acquisition

Stefan Stortecky: Conceptualization, Methodology, Validation, Investigation, Resources, Writing Original Draft, Visualization, Supervision, Project administration, Funding acquisition 


\section{DiSCLOSURES}

S. Stortecky has received research grants to the institution from Edwards Lifesciences, Medtronic, Abbott Vascular and Boston Scientific, speaker fees from Boston Scientific and consultant fees from BTG and Teleflex. D. Heg is affiliated with CTU Bern, University of Bern, which has a staff policy of not accepting honoraria or consultancy fees. However, CTU Bern is involved in design, conduct, or analysis of clinical studies funded by not-for-profit and for-profit organizations. In particular, pharmaceutical and medical device companies provide direct funding to some of these studies. For an up-to-date list of CTU Bern's conflicts of interest see http://www.ctu.unibe.ch/research/declaration_of_interest/index_eng.html. T. Okuno reports personal fees from Abbott, outside the submitted work. L. Räber has received Research grants to the institution by Abbott Vascular, Biotronik, Boston Scientific, Heartflow, Sanofi, Regeneron and Consultation/Speaker Fees by Abbott, Amgen, AstraZeneca, Canon, CSL Behring, Sanofi, Vifor. T. Pilgrim has received research grants to the institution from Edwards Lifesciences, Biotronik and Boston Scientific and speaker fees from Boston Scientific and Biotronik. S. Windecker reports research and educational grants to the institution from Abbott, Amgen, BMS, Bayer, Boston Scientific, Biotronik, Cardinal Health, CardioValve, CSL Behring, Daiichi Sankyo, Edwards Lifesciences, Johnson\&Johnson, Medtronic, Querbet, Polares, Sanofi, Terumo, Sinomed. Stephan Windecker serves as unpaid member of the steering / executive group of trials funded by Abbott, Abiomed, Amgen, BMS, Boston Scientific, Biotronik, Cardiovalve, Edwards Lifesciences, MedAlliance, Medtronic, Polares, Sinomed, V-Wave and Xeltis, but has not received personal payments by any pharmaceutical company or device manufacturer. He is also member of the steering / executive committee group of several investigated-initiated trials that receive funding by industry without impact on his personal remuneration. All other authors have no conflicts of interest to declare. 
References

1. Engelman DT, Ali W Ben, Williams JB, Perrault LP, Reddy VS, Arora RC, Roselli EE, Khoynezhad A, Gerdisch M, Levy JH, Lobdell K, Fletcher N, Kirsch M, Nelson G, Engelman RM, Gregory AJ, Boyle EM. Guidelines for Perioperative Care in Cardiac Surgery: Enhanced Recovery after Surgery Society Recommendations. JAMA Surg 2019;154:755-766.

2. Rauch B, Davos CH, Doherty P, Saure D, Metzendorf MI, Salzwedel A, Völler H, Jensen K, Schmid JP. The prognostic effect of cardiac rehabilitation in the era of acute revascularisation and statin therapy: A systematic review and meta-analysis of randomized and non-randomized studies - The Cardiac Rehabilitation Outcome Study (CROS). Eur J Prev Cardiol 2016;23:1914-1939.

3. Sibilitz KL, Berg SK, Tang LH, Risom SS, Gluud C, Lindschou J, Kober L, Hassager C, Taylor RS, Zwisler AD. Exercise-based cardiac rehabilitation for adults after heart valve surgery. Cochrane Database Syst Rev 2016.

4. Winkel MG, Stortecky S, Wenaweser P. Transcatheter Aortic Valve Implantation Current Indications and Future Directions. Front Cardiovasc Med 2019;6:179.

5. Lauck SB, Wood DA, Achtem L, Baumbusch J, Boone RH, Cheung A, Dvir D, Stub D, Tan JS, Ye J, Webb JG. Risk Stratification and Clinical Pathways to Optimize Length of Stay After Transcatheter Aortic Valve Replacement. Can J Cardiol 2014;30:1583-1587.

6. Lauck SB, Wood DA, Baumbusch J, Kwon JY, Stub D, Achtem L, Blanke P, Boone RH, Cheung A, Dvir D, Gibson JA, Lee B, Leipsic J, Moss R, Perlman G, Polderman J, Ramanathan K, Ye J, Webb JG. Vancouver transcatheter aortic valve replacement clinical pathway. Circ Cardiovasc Qual Outcomes 2016;9:312-321.

7. Wood DA, Lauck SB, Cairns JA, Humphries KH, Cook R, Welsh R, Leipsic J, Genereux 
P, Moss R, Jue J, Blanke P, Cheung A, Ye J, Dvir D, Umedaly H, Klein R, Rondi K, Poulter

R, Stub D, Barbanti M, Fahmy P, Htun N, Murdoch D, Prakash R, Barker M, Nickel K,

Thakkar J, Sathananthan J, Tyrell B, Al-Qoofi F, Velianou JL, Natarajan MK, Wijeysundera HC, Radhakrishnan S, Horlick E, Osten M, Buller C, Peterson M, Asgar A, Palisaitis D, Masson JB, Kodali S, Nazif T, Thourani V, Babaliaros VC, Cohen DJ, Park JE, Leon MB, Webb JG. The Vancouver 3M (Multidisciplinary, Multimodality, But Minimalist) Clinical Pathway Facilitates Safe Next-Day Discharge Home at Low-, Medium-, and High-Volume Transfemoral Transcatheter Aortic Valve Replacement Centers: The 3M TAVR Study. $J$ Am Coll Cardiol Intv 2019;12:459-469.

8. Wenaweser P, Pilgrim T, Kadner A, Huber C, Stortecky S, Buellesfeld L, Khattab AA, Meuli F, Roth N, Eberle B, Erdös G, Brinks H, Kalesan B, Meier B, Jni P, Carrel T, Windecker S. Clinical outcomes of patients with severe aortic stenosis at increased surgical risk according to treatment modality. JAm Coll Cardiol 2011;58:2151-2162.

9. Kappetein AP, Head SJ, Généreux P, Piazza N, Mieghem NM Van, Blackstone EH, Brott TG, Cohen DJ, Cutlip DE, Es GA Van, Hahn RT, Kirtane AJ, Krucoff MW, Kodali S, MacK MJ, Mehran R, Rodés-Cabau J, Vranckx P, Webb JG, Windecker S, Serruys PW, Leon MB. Updated standardized endpoint definitions for transcatheter aortic valve implantation: The Valve Academic Research Consortium-2 consensus document. J Thorac Cardiovasc Surg 2013;145:6-23.

10. Stoicea N, You T, Eiterman A, Hartwell C, Davila V, Marjoribanks S, Florescu C, Bergese SD, Rogers B. Perspectives of Post-Acute Transition of Care for Cardiac Surgery Patients. Front Cardiovasc Med 2017;4:1-8.

\section{Ribeiro GS, Melo RD, Deresz LF, Dal Lago P, Pontes MRN, Karsten M. Cardiac} rehabilitation programme after transcatheter aortic valve implantation versus surgical aortic 
valve replacement: Systematic review and meta-analysis. Eur J Prev Cardiol 2017;24:688697.

12. Anayo L, Rogers P, Long L, Dalby M, Taylor R. Exercise-based cardiac rehabilitation for patients following open surgical aortic valve replacement and transcatheter aortic valve implant: A systematic review and meta-analysis. Open Heart 2019;6:1-8.

13. Hansen TB, Berg SK, Sibilitz KL, Søgaard R, Thygesen LC, Yazbeck AM, Zwisler AD. Availability of, referral to and participation in exercise-based cardiac rehabilitation after heart valve surgery: Results from the national CopenHeart survey. Eur J Prev Cardiol $2015 ; 22: 710-718$.

14. Tarro Genta F. Cardiac Rehabilitation for Transcatheter Aortic Valve Replacement. Clin Geriatr Med 2019;35:539-548.

15. Mehilli J, Chandrasekhar J, Sartori S, Chieffo A, Petronio AS, Lefèvre T, Presbitero P, Capranzano P, Tchetche D, Iadanza A, Sardella G, Mieghem NM Van, Meliga E, Dumonteil N, Fraccaro C, Trabattoni D, Jochheim D, Zadrozny M, Mikhail GW, Sharma S, Ferrer MC, Naber C, Kievit P, Moalem K, Baber U, Snyder C, Sharma M, Morice MC, Mehran R. Impact of Discharge Location After Transcatheter Aortic Valve Replacement on 1-Year Outcomes in Women: Results From the WIN-TAVI Registry. Can J Cardiol 2019;35:199-207.

16. Shah RM, Hirji SA, Jolissaint JS, Lander HL, Shah PB, Pelletier MP, Sobieszczyk PS, Berry NC, Shook DC, Nyman CB, Bhatt DL, Body S, Kaneko T. Comparison of Sex-Based Differences in Home or Nonhome Discharge Utilization of Rehabilitative Services and Outcomes Following Transcatheter Aortic Valve Implantation in the United States. Am J Cardiol 2019;123:1983-1991.

17. Wallman KK ed. Older Americans 2016: Key Indicators of Wellbeing. Federal 
Interagency Forum on Aging-Related Statistics. Washington, DC: U.S. Government Printing Office; 2016. Available at: http://www.agingstats.gov. 


\section{Figure LEGENDS}

Figure 1: Patient Flow Diagram

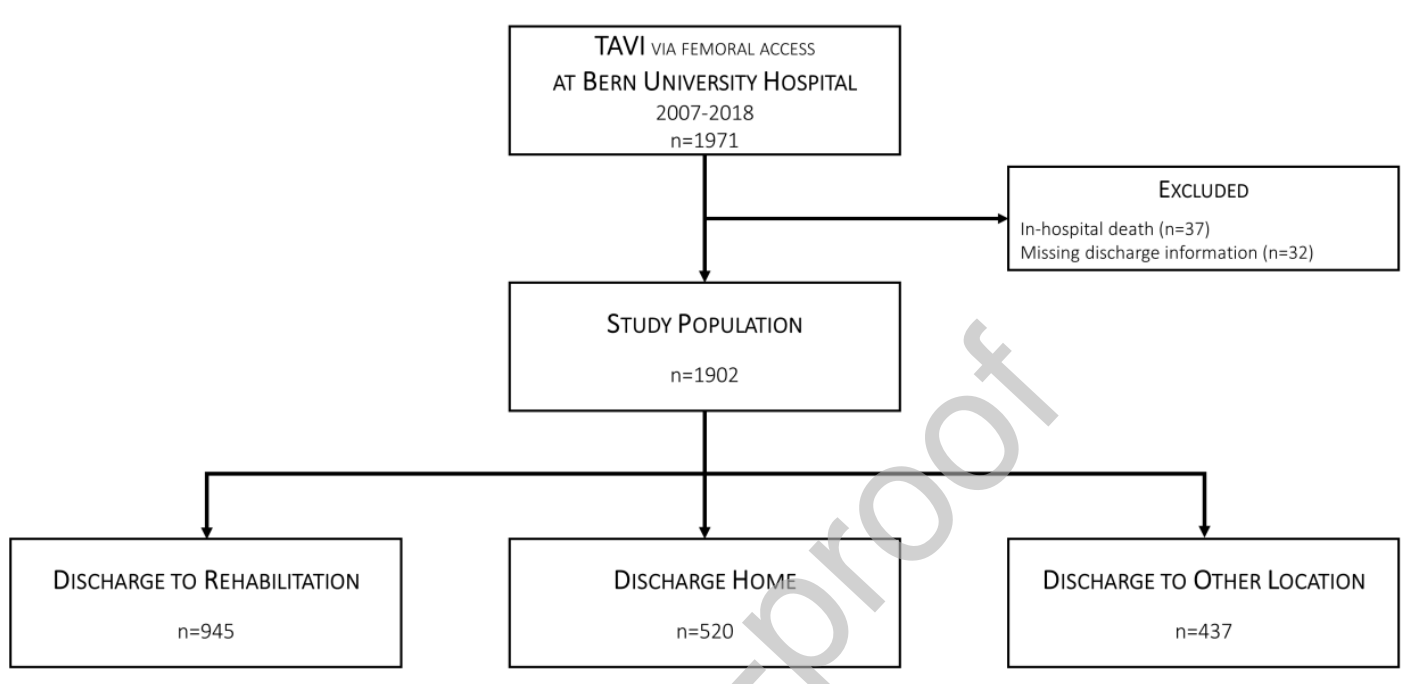


Figure 2: Discharge location over time

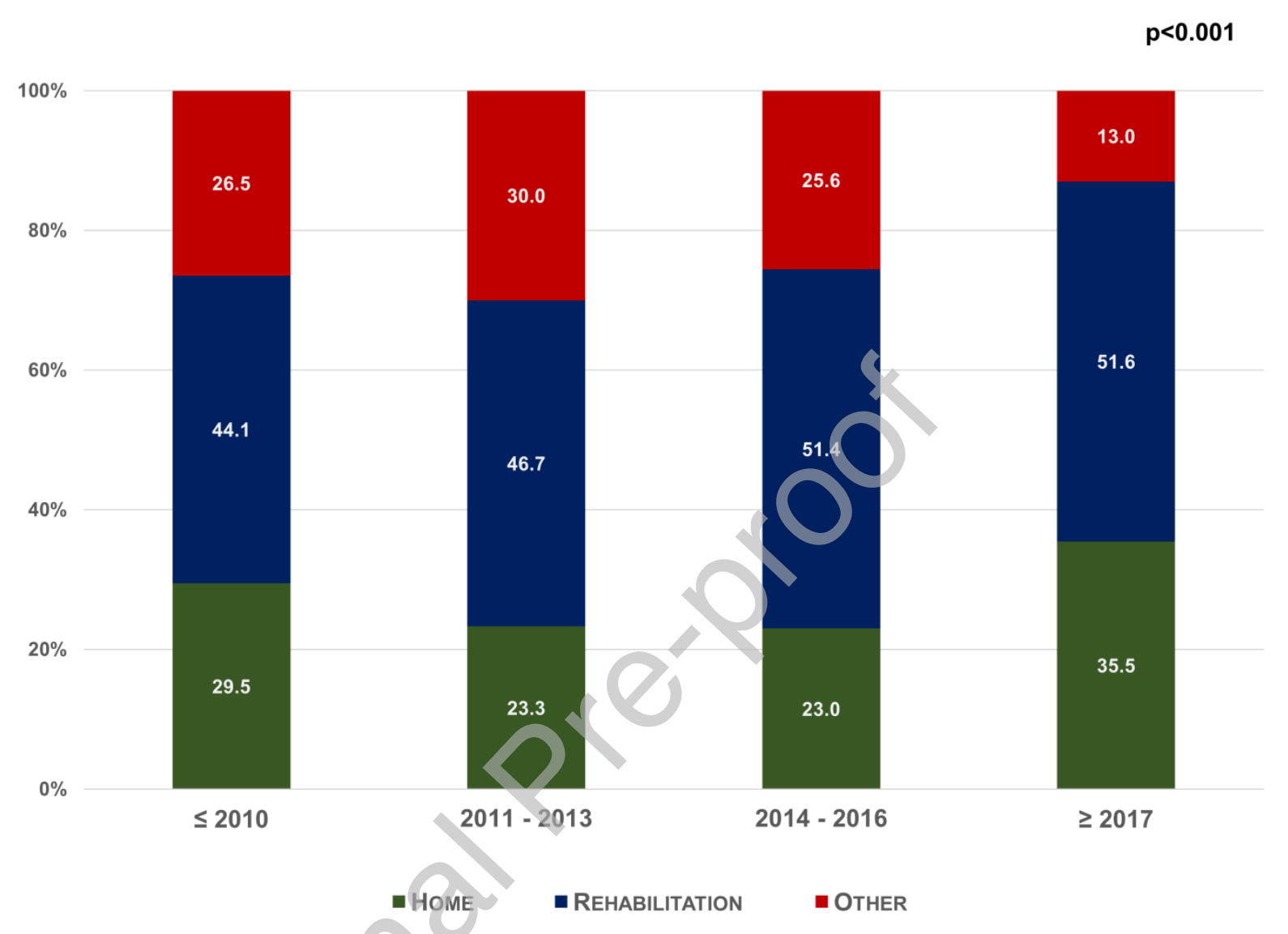


Figure 3: All-cause death according to discharge location

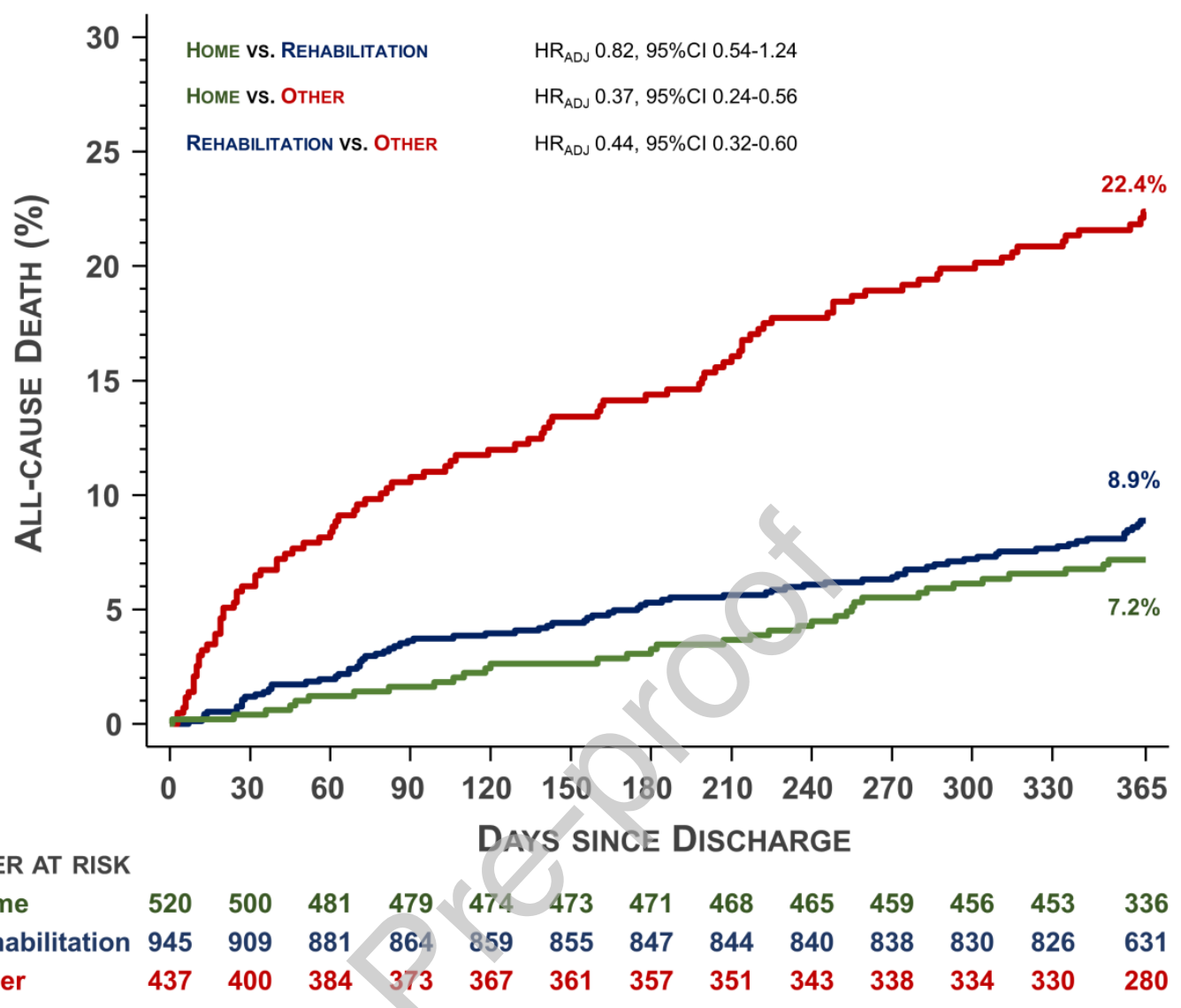




\begin{tabular}{|c|c|c|c|c|c|c|c|}
\hline \multicolumn{2}{|c|}{ Baseline Clinical Characteristics } & \multirow[b]{2}{*}{ HOME } & \multirow[b]{2}{*}{ REHABILITATION } & \multirow[b]{2}{*}{ OTHER } & & & \\
\hline & ALL PATIENTS & & & & \multicolumn{3}{|c|}{ PAIRWISE P-VALUE } \\
\hline Variable & $(N=1902)$ & $(N=520)$ & $(N=945)$ & $(N=437)$ & $\begin{array}{c}\text { Home vs } \\
\text { Rehab }\end{array}$ & $\begin{array}{c}\text { Home vs } \\
\text { Other }\end{array}$ & $\begin{array}{c}\text { Rehab vs } \\
\text { Other }\end{array}$ \\
\hline Age (years) & $82.3 \pm 6.0$ & $80.8 \pm 6.5$ & $82.9 \pm 5.4$ & $82.8 \pm 6.4$ & $<0.001$ & $<0.001$ & 0.90 \\
\hline Women & 995 (52.3\%) & $194(37.3 \%)$ & $564(59.7 \%)$ & $237(54.2 \%)$ & $<0.001$ & $<0.001$ & 0.06 \\
\hline Body mass index $(\mathrm{kg} / \mathrm{cm} 2)$ & $26.6 \pm 5.3$ & $26.7 \pm 5.2$ & $26.5 \pm 5.4$ & $26.7 \pm 5.1$ & 0.38 & 0.99 & 0.40 \\
\hline Diabetes mellitus & $491(25.8 \%)$ & $133(25.6 \%)$ & $237(25.1 \%)$ & $121(27.7 \%)$ & 0.85 & 0.46 & 0.32 \\
\hline Previous pacemaker implantation & $162(8.5 \%)$ & $52(10.0 \%)$ & $73(7.7 \%)$ & $37(8.5 \%)$ & 0.14 & 0.44 & 0.67 \\
\hline History of myocardial infarction & $284(14.9 \%)$ & $78(15.0 \%)$ & $129(13.7 \%)$ & $77(17.6 \%)$ & 0.48 & 0.29 & 0.06 \\
\hline History of cardiac surgery & $237(12.5 \%)$ & $87(16.7 \%)$ & $106(11.2 \%)$ & $44(10.1 \%)$ & 0.004 & 0.003 & 0.58 \\
\hline History of cerebrovascular accident & $217(11.4 \%)$ & $47(9.0 \%)$ & $113(12.0 \%)$ & $57(13.0 \%)$ & 0.096 & 0.06 & 0.60 \\
\hline Peripheral artery disease & $185(9.7 \%)$ & $48(9.2 \%)$ & $85(9.0 \%)$ & $52(11.9 \%)$ & 0.92 & 0.20 & 0.10 \\
\hline COPD & $219(11.5 \%)$ & $65(12.5 \%)$ & $95(10.1 \%)$ & $59(13.5 \%)$ & 0.16 & 0.70 & 0.066 \\
\hline Coronary artery disease & $1153(60.6 \%)$ & $332(63.8 \%)$ & $551(58.3 \%)$ & $270(61.8 \%)$ & 0.039 & 0.55 & 0.24 \\
\hline \multicolumn{8}{|l|}{ Echocardiographic Parameters } \\
\hline LVEF (\%) & $54.8 \pm 13.5$ & $55.4 \pm 12.8$ & $55.5 \pm 13.5$ & $52.4 \pm 14.3$ & 0.92 & 0.003 & 0.001 \\
\hline Mean gradient (mmHg) & $41.4 \pm 16.8$ & $41.7 \pm 15.7$ & $41.7 \pm 17.2$ & $40.6 \pm 17.3$ & 0.99 & 0.40 & 0.38 \\
\hline Symptoms on admission & & 8 & & & & & \\
\hline NYHA I or II & $575(30.2 \%)$ & 204 (39.2\%) & $271(28.7 \%)$ & $100(22.9 \%)$ & $<0.001$ & $<0.001$ & 0.026 \\
\hline NYHA III or IV & $1326(69.8 \%)$ & $316(60.8 \%)$ & 674 (71.3\%) & $336(77.1 \%)$ & $<0.001$ & $<0.001$ & 0.026 \\
\hline No Angina & 1477 (77.7\%) & 418 (80.4\%) & 736 (77.9\%) & $323(73.9 \%)$ & 0.29 & 0.020 & 0.12 \\
\hline CCS I or II & $289(15.2 \%)$ & $73(14.0 \%)$ & $141(14.9 \%)$ & 75 (17.2\%) & 0.70 & 0.21 & 0.30 \\
\hline CCS III or IV & $136(7.2 \%)$ & $29(5.6 \%)$ & $68(7.2 \%)$ & $39(8.9 \%)$ & 0.27 & 0.057 & 0.28 \\
\hline \multicolumn{8}{|l|}{ Risk Assessment } \\
\hline STS PROM (\%) & $5.5 \pm 3.8$ & $4.5 \pm 3.0$ & $5.5 \pm 3.8$ & $6.6 \pm 4.4$ & $<0.001$ & $<0.001$ & $<0.001$ \\
\hline & $x>->$ & & & & & & \\
\hline
\end{tabular}




\begin{tabular}{|c|c|c|c|c|c|c|c|}
\hline \multirow[t]{2}{*}{ TABLE 2} & ICTERISTICS ANL & Jospital Cou & & & & & \\
\hline & ALL PATIENTS & HOME & REHABILITATION & OTHER & \multicolumn{3}{|c|}{ PAIRWISE P-VALUE } \\
\hline Variable & $(N=1902)$ & $(N=520)$ & $(N=945)$ & $(\mathrm{N}=437)$ & $\begin{array}{c}\text { Home vs } \\
\text { Rehab }\end{array}$ & $\begin{array}{c}\text { Home vs } \\
\text { Other }\end{array}$ & $\begin{array}{l}\text { Rehab vs } \\
\text { Other }\end{array}$ \\
\hline Procedure time (min) & $58.2 \pm 30.4$ & $54.6 \pm 28.7$ & $56.7 \pm 27.3$ & $65.9 \pm 36.7$ & 0.16 & $<0.001$ & $<0.001$ \\
\hline Total contrast administered (cc) & $177.8 \pm 85.2$ & $171.3 \pm 81.3$ & $172.2 \pm 77.1$ & $197.9 \pm 101.6$ & 0.84 & $<0.001$ & $<0.001$ \\
\hline General anesthesia & $256(13.5 \%)$ & $65(12.5 \%)$ & $111(11.7 \%)$ & $80(18.3 \%)$ & 0.68 & 0.014 & 0.001 \\
\hline \multicolumn{8}{|l|}{ Device Features } \\
\hline Medtronic CoreValve & $415(21.9 \%)$ & $101(19.4 \%)$ & $196(20.8 \%)$ & $118(27.1 \%)$ & 0.59 & 0.005 & 0.011 \\
\hline Edwards Sapien XT & $241(12.7 \%)$ & $58(11.2 \%)$ & $107(11.3 \%)$ & $76(17.4 \%)$ & 0.93 & 0.007 & 0.003 \\
\hline Symetis Acurate / - NEO & $154(8.1 \%)$ & $45(8.7 \%)$ & $86(9.1 \%)$ & $23(5.3 \%)$ & 0.85 & 0.044 & 0.013 \\
\hline SJM Portico & $24(1.3 \%)$ & $3(0.6 \%)$ & $15(1.6 \%)$ & $6(1.4 \%)$ & 0.14 & 0.31 & 1.00 \\
\hline Direct Flow Medical & $1(0.1 \%)$ & $0(0.0 \%)$ & $0(0.0 \%)$ & $1(0.2 \%)$ & & 0.46 & 0.32 \\
\hline Edwards Sapien 3 & $589(31.0 \%)$ & $181(34.8 \%)$ & $294(31.2 \%)$ & $114(26.1 \%)$ & 0.16 & 0.004 & 0.057 \\
\hline BSC Lotus & $128(6.7 \%)$ & $39(7.5 \%)$ & $57(6.0 \%)$ & $32(7.3 \%)$ & 0.32 & 1.00 & 0.41 \\
\hline Medtronic Evolut R & $225(11.8 \%)$ & $60(11.5 \%)$ & $115(12.2 \%)$ & $50(11.5 \%)$ & 0.74 & 1.00 & 0.72 \\
\hline Lotus Edge & $5(0.3 \%)$ & $0(0.0 \%)$ & $4(0.4 \%)$ & $1(0.2 \%)$ & 0.30 & 0.46 & 1.00 \\
\hline Evolut PRO & $108(5.7 \%)$ & $29(5.6 \%)$ & $65(6.9 \%)$ & $14(3.2 \%)$ & 0.37 & 0.086 & 0.006 \\
\hline Edwards Centera & $9(0.5 \%)$ & $4(0.8 \%)$ & $4(0.4 \%)$ & $1(0.2 \%)$ & 0.47 & 0.38 & 1.00 \\
\hline Aortic regurgitation grade & & ( & & & 0.66 & 0.17 & 0.37 \\
\hline none & $477(25.2 \%)$ & $138(26.6 \%)$ & $229(24.4 \%)$ & $110(25.5 \%)$ & & & \\
\hline mild & $1273(67.4 \%)$ & $350(67.4 \%)$ & $641(68.3 \%)$ & $282(65.3 \%)$ & & & \\
\hline moderate & $137(7.2 \%)$ & $30(5.8 \%)$ & $67(7.1 \%)$ & $40(9.3 \%)$ & & & \\
\hline severe & $3(0.2 \%)$ & $1(0.2 \%)$ & $2(0.2 \%)$ & $0(0.0 \%)$ & & & \\
\hline \multicolumn{8}{|l|}{ In Hospital Course } \\
\hline Packed Red Blood Cells (PRBC) & $226(11.9 \%)$ & $39(7.5 \%)$ & $109(11.5 \%)$ & $78(17.8 \%)$ & 0.014 & $<0.001$ & 0.002 \\
\hline Total number of PRBC & $2.0(1.0 ; 3.0)$ & $2.0(1.0 ; 2.0)$ & $2.0(1.0 ; 3.0)$ & $2.0(2.0 ; 4.0)$ & 0.25 & 0.008 & 0.037 \\
\hline Overall In-Hospital Stay (days) & $8.3 \pm 4.1$ & $7.2 \pm 3.1$ & $8.9 \pm 3.8$ & $8.5 \pm 5.5$ & $<0.001$ & $<0.001$ & 0.17 \\
\hline Intensive care unit & $0.2 \pm 0.9$ & $0.04 \pm 0.3$ & $0.1 \pm 0.5$ & $0.4 \pm 1.6$ & 0.017 & $<0.001$ & $<0.001$ \\
\hline Intermediate care & $2.8 \pm 2.1$ & $2.3 \pm 1.8$ & $2.7 \pm 1.9$ & $3.7 \pm 2.7$ & $<0.001$ & $<0.001$ & $<0.001$ \\
\hline General ward & $5.4 \pm 3.5$ & $4.8 \pm 2.5$ & $6.1 \pm 3.3$ & $4.5 \pm 4.4$ & $<0.001$ & 0.11 & $<0.001$ \\
\hline
\end{tabular}




\section{TABLE 3 OUtCOMES AT 1 YeAR POST-DISCHARGE}

\begin{tabular}{|c|c|c|c|c|c|c|c|c|c|}
\hline \multirow[b]{3}{*}{ Variable } & \multirow{3}{*}{$\begin{array}{c}\text { HOME } \\
(N=520)\end{array}$} & \multirow{3}{*}{$\begin{array}{c}\text { REHABILITATIO } \\
\mathbf{N} \\
\\
(N=945)\end{array}$} & \multirow{3}{*}{$\begin{array}{c}\text { OTHER } \\
(\mathrm{N}=437)\end{array}$} & \multicolumn{6}{|c|}{ ADJUSTED HAZARD RATIOS [95\% CONFIDENCE INTERVALS] } \\
\hline & & & & \multicolumn{2}{|c|}{ Home vs Rehab } & \multicolumn{2}{|c|}{ Home vs Other } & \multicolumn{2}{|c|}{ Rehab vs Other } \\
\hline & & & & Adj.HR [95\% Cl] & $\begin{array}{c}\mathrm{p}- \\
\text { value }\end{array}$ & Adj.HR $[95 \% \mathrm{Cl}]$ & $\begin{array}{c}\mathrm{p}- \\
\text { value }\end{array}$ & Adj.HR [95\% Cl] & $\begin{array}{c}\mathrm{p}- \\
\text { value }\end{array}$ \\
\hline Mortality & $\begin{array}{c}35 \\
(7.2 \%) \\
\end{array}$ & $79(8.9 \%)$ & $\begin{array}{c}94 \\
(22.4 \%) \\
\end{array}$ & $0.82(0.54-1.24)$ & 0.35 & $0.37(0.24-0.56)$ & $<0.001$ & $0.44(0.32-0.60)$ & $<0.001$ \\
\hline Cardiac mortality & $\begin{array}{c}22 \\
(4.6 \%) \\
\end{array}$ & $51(5.8 \%)$ & $\begin{array}{c}61 \\
(15.0 \%) \\
\end{array}$ & $0.79(0.47-1.34)$ & 0.38 & $0.42(0.25-0.71)$ & 0.001 & $0.45(0.30-0.66)$ & $<0.001$ \\
\hline Cerebrovascular accident & $\begin{array}{c}14 \\
(2.9 \%) \\
\end{array}$ & $24(2.7 \%)$ & $10(2.7 \%)$ & $1.04(0.52-2.08)$ & 0.91 & $1.15(0.47-2.80)$ & 0.77 & $0.98(0.46-2.10)$ & 0.96 \\
\hline Disabling stroke & $9(1.9 \%)$ & $10(1.1 \%)$ & $7(1.9 \%)$ & 12 & & & & & \\
\hline Non-disabling stroke & $3(0.6 \%)$ & $9(1.0 \%)$ & $1(0.3 \%)$ & 3 & & & & & \\
\hline Myocardial infarction (MI) & $6(1.2 \%)$ & $12(1.4 \%)$ & $3(0.8 \%)$ & & & & & & \\
\hline Spontaneous MI & $5(1.1 \%)$ & $12(1.4 \%)$ & $3(0.8 \%)$ & $\nabla$ & & & & & \\
\hline Bleeding & $\begin{array}{c}37 \\
(7.7 \%)\end{array}$ & $69(7.8 \%)$ & $\begin{array}{c}49 \\
(12.7 \%) \\
\end{array}$ & $0.93(0.61-1.41)$ & 0.73 & $0.48(0.30-0.76)$ & 0.002 & $0.66(0.45-0.96)$ & 0.030 \\
\hline Life-threatening bleeding & $\begin{array}{c}11 \\
(2.3 \%) \\
\end{array}$ & $20(2.3 \%)$ & $17(4.7 \%)$ & $0.95(0.43-2.06)$ & 0.89 & $0.48(0.21-1.10)$ & 0.084 & $0.57(0.29-1.11)$ & 0.099 \\
\hline Major bleeding & $\begin{array}{c}10 \\
(2.1 \%)\end{array}$ & $25(2.8 \%)$ & $16(4.1 \%)$ & $0.73(0.34-1.58)$ & 0.42 & $0.44(0.19-1.04)$ & 0.060 & $0.77(0.40-1.48)$ & 0.44 \\
\hline $\begin{array}{l}\text { Permanent Pacemaker } \\
\text { Implantation }\end{array}$ & $9(1.9 \%)$ & $22(2.5 \%)$ & $17(4.5 \%)$ & $0.76(0.34-1.69)$ & 0.50 & $0.53(0.22-1.27)$ & 0.16 & $0.68(0.35-1.31)$ & 0.25 \\
\hline
\end{tabular}

Depicted are number of events occurring from discharge to one year after discharge (\% from life-table estimate). Estimates from Cox's regressions.

Adjusted Cox's regression: adjusted for age, sex, Society of Thoracic Surgeons (STS) score, atrial fibrillation, left ventricular ejection fraction, year of transcatheter aortic valve implantation ( $\leq 2010,2011-2013,>2014)$; regurgitation aortic, mitral and tricuspid valves; and index hospitalization events: cerebrovascular event, vascular complication, life-threatening or major bleeding nonprocedural, acute kidney injury stage 2 or 3 ; number of days in the hospital before discharge ( $\leq 3$ vs $4-6$ vs $7-10$ vs $>10$ days). Assuming no risk for missing variables and no adjusted analyses with less than ten events. 